\title{
Effect of drought stress on some growth, morphological, physiological, and biochemical parameters of two different populations of Quercus
} brantii

\author{
Shahram Jafarnia(1), \\ Moslem Akbarinia ${ }^{(1)}$, \\ Batool Hosseinpour ${ }^{(2)}$, \\ Seyed AM Modarres Sanavi ${ }^{(3)}$, \\ Seyed A Salami ${ }^{(4)}$
}

(1) Department of Forestry, Faculty of Natural Resources, Tarbiat Modares University, P. O. Box 14115-111 (Iran); (2) Department of Agriculture, Iranian Research Organization for Science and Technology (IROST), P. O. Box 3353-5111, Tehran (Iran); (3) Department of Agronomy, Faculty of Agriculture, Tarbiat Modares University, P. O. Box 14115336, Tehran (Iran); (4) Department of Horticultural Sciences, Faculty of Agriculture and Natural Resources, University of Tehran, P. O. Box 41111, Tehran (Iran)

@ Moslem Akbarinia

(akbarinia.m@gmail.com)

Received: May 19, 2017 - Accepted: Nov 22, 2017

Citation: Jafarnia S, Akbarinia $M$, Hosseinpour B, Modarres Sanavi SAM, Salami SA (2018). Effect of drought stress on some growth, morphological, physiological, and biochemical parameters of two different populations of Quercus brantii. iForest 11: 212-220. - doi: 10.3832/ifor2496-010 [online 2018-03-01]

Communicated by: Claudia Cocozza
In recent years, drought-induced tree mortality has occurred in the oak forests of the Zagros Mountains (western Iran). The impacts of climate change induced by drought stress have been most acutely experienced by two populations of Persian oaks (Quercus brantii Lindl) grown in the western provinces (Ilam and Lorestan) of the Zagros region. We surveyed growth, physiological, and biochemical responses of one-year-old Persian oak seedlings from Melasyah (Ilam) and Chegeni (Lorestan) provenances, which were subjected to three watering regimes $(100 \%, 40 \%$, and $20 \%$ of field capacity) in a greenhouse. The severe drought stress decreased the diameter and height growth, total biomass, net photosynthesis, gas exchange, xylem water potential, maximum Rubisco activity $\left(V_{c \max }\right)$ as well as the maximum PSIl photochemical efficiency of the oak seedlings in both populations, but the rate of decrease was greater in Chegeni seedlings as compared to Melasyah seedlings. Although proline and soluble sugar contents significantly increased in response to drought in both populations under stress, the rate of increase was higher in Melasyah seedlings as compared to Chegeni seedlings. In addition, the activities of peroxidase, superoxide dismutase, catalase, and ascorbic peroxidase as well as that of phenylalanine ammonia lyase were promoted in both populations under drought stress. However, the incremental rate was higher in the Melasyah population than in the Chegeni population. Under severe drought stress, the MDA content, electrolyte leakage, the content of hydrogen peroxide, and superoxide radical significantly increased in both the populations. The rate of increase, however, was higher in the Chegeni population. Under drought stress, the total phenol and flavonoid contents of Melasyah seedlings were higher than those of Chegeni seedlings. The results showed that Chegeni seedlings are more sensitive than Melasyah seedlings when exposed to a water limitation stress. Our findings suggest that the climate conditions of the Persian oak stands should be considered by nursery managers while creating establishment and restoration programs.

Keywords: Drought Stress, Persian Oak, Zagros Mountain, Provenance, Drought Resistance

\section{Introduction}

In recent years, the negative impacts of climate change on forest trees has intensified (Sturrock et al. 2011), thus exposing forests to increasingly stressful conditions, such as heat and drought (La Porta et al. 2008). The most alarming outcome of climate change is the increased number of trees dying off because of drought. During recent years, many trees have been lost in the forests of the Zagros Mountains, located in the western provinces of Iran (Ilam, Lorestan, and Kermanshah), as a result of decreased precipitation and increased temperature in the region. The $\mathrm{Za}$ gros forests cover an area of 5 million hectares (about $40 \%$ of all Iranian forests), and represent the widest forest region of the country (Ahmadi et al. 2014). Persian oak (Quercus brantii Lindl.) is the dominant tree species in these forests and is extensively distributed throughout the mountains. Drought has also increased the vul- nerability of trees to charcoal disease (Ghanbary et al. 2017).

The survival and growth of Persian oaks depend on their tolerance to drought stress (Ghanbary et al. 2017). Therefore, conservation activities aimed at preserving Persian oaks in the damaged Zagros forests might greatly benefit from the selection of individuals or provenances more tolerant to drought.

Drought is one of the most important limitation factors for growth and plant production. Under drought stress, some disorder generally occurs in most physiological processes, such as decreases in photosynthesis rate and growth (Hu et al. 2010), stomatal conductance (Hoshika et al. 2013), as well as cell dehydration (Manes et al. 2006) and chlorophyll degradation (Fini et al. 2013). Besides, biochemical reactions are part of the plant's response to environmental stress (Porth et al. 2005). Plants respond to drought stress using a combina- 
tion of biochemical processes (Ahmed et al. 2009). Proline and soluble sugars are overproduced in plants in response to drought stress. Proline and carbohydrates act as osmolytes to maintain water in the cytoplasm (Ahmed et al. 2009). Furthermore, they prevent protein denaturation and cell membrane damage, and induce stability in the structure of enzymatic proteins, thereby preserving their activity (Hessini et al. 2009).

The production of reactive oxygen species (ROS), including superoxide radicals and hydrogen peroxide, is an important biochemical response to oxidative stress (Ebadzad et al. 2015). High ROS concentrations can disrupt normal plant metabolism damaging lipids, proteins, chlorophyll, and nucleic acids (Talbi et al. 2015). ROS directly damage cell membrane phospholipids and increases lipid peroxidation, which can be determined by the content of malondialdehyde (MDA) by-products (Zarafshar et al. 2014). On the other hand, oxidative damage to cell membranes results in electrolyte leakage (EL) and, ultimately, in cell death (Shukla et al. 2012).

Plants use different enzymatic and nonenzymatic systems to control ROS production induced by drought stress. The most important antioxidant enzymes include superoxide dismutase (SOD), catalase and peroxidases (POXs), glutathione reductase, and ascorbate peroxidase (APX) to prevent cell damage (Liu et al. 2011). In addition, phenolic components - especially flavonoids and phenylalanine ammonia lyase (PAL) - form another class of plant defense molecules that respond to drought stress (Ahmadi et al. 2014). In fact, PAL is the primer of the phenylpropanoid pathway that finally leads to phenolic components biosynthesis.

Although previous studies focused on growth and physiological responses of oak species to drought stress (Manes et al. 2006, Cotrozzi et al. 2016), there is limited data concerning the effect of drought stress on morphological, physiological, and biochemical responses of the Persian oak. In this study, Persian oak seedlings were selected from two provinces in the Zagros region with different precipitation regimes, and subjected to different levels of drought stress. The growth, physiological, and biochemical responses of the seedlings were measured to compare the level of drought tolerance between and within the individuals of the two populations. Here,

Tab. 1 - Climatic characteristics of the provenances selected in this study. $(\ddagger)$ : 10-yearannual means according to data of meteorological stations of each province.

\begin{tabular}{|c|c|c|c|c|c|}
\hline Province & Provenance & $\begin{array}{l}\text { Altitude } \\
\text { (m.a.s.l.) }\end{array}$ & Coordinates & $\begin{array}{c}\text { Temp }{ }^{())} \\
\left({ }^{\circ} \mathrm{C}\right)\end{array}$ & $\begin{array}{l}\text { Rainfall (†) } \\
(\mathrm{mm})\end{array}$ \\
\hline Ilam & Melasyah & 1490 & $\begin{array}{l}33^{\circ} 43^{\prime} 04^{\prime \prime} \mathrm{N} \\
46^{\circ} 13^{\prime} 67^{\prime \prime} \mathrm{E}\end{array}$ & 19.8 & 235 \\
\hline Lorestan & Chegeni & 1975 & $\begin{array}{l}33^{\circ} 27^{\prime} 20^{\prime \prime} \mathrm{N} \\
48^{\circ} 11^{\prime} 28^{\prime \prime} \mathrm{E}\end{array}$ & 16.4 & 409 \\
\hline
\end{tabular}

treatment was conducted in four replications and 10 seedlings were used in each replication. Seedlings of each provenance were imposed to three watering regimes including 100\% (W: control), 40\% (M: moderate), and $20 \%$ (S: severe) of soil field capacity. The stress treatments continued for three months.

\section{Growth parameters}

At the end of the experiment, the stem diameter and height of each seedling were measured. Then, the seedlings were removed from their pots and the soil around the roots was washed away. Each plantlet was divided into roots, stems, and leaves. Biomass samples were dried at $70^{\circ} \mathrm{C}$ for 48 hours and weighted (Zarafshar et al. 2014). The root/shoot ratio was then calculated. temperature compared to the northern area. We selected Ilam and Lorestan provinces from the southern and central Zagros Mountains, respectively. Ilam province has a lower average annual precipitation, higher mean temperature, and longer dry season, compared with Lorestan province. The general climatic characteristics of both provinces are presented in Tab. 1.

Ten healthy Persian oak individuals were randomly selected from Chegeni (Lorestan province) and Melasyah (Ilam province) provenances, and their healthy and mature seeds were collected (Zarafshar et al. 2014). The sampled seeds were surfacesterilized with 3.5\% Na-hypochlorite for 10 minutes and then rinsed three times with sterile distilled water. The sterilized seeds were planted in polyethylene pots $(10 \times 15$ $\mathrm{cm}$ ) containing a mixture of compost and perlite $(3: 1 \mathrm{v} / \mathrm{v})$. The seeds were germinated under controlled condition including a light period of 13 hours, mean temperature of $25 \pm 2{ }^{\circ} \mathrm{C}$, and optical photosynthetic radiation of $1200 \mu \mathrm{mol} \mathrm{m}^{-2} \mathrm{~S}^{-1}$ for a one-year period with daily irrigation. The grown seedlings were replanted into plastic pots $(5 \mathrm{~L})$ containing sandy loam soil ( $51 \%$ sand, $34 \%$ silt, $15 \%$ clay, $1.25 \%$ organic matter, $0.34 \% \mathrm{~N}, 12.52 \mathrm{mg} \mathrm{kg}^{-1}$ available phosphorus, $174 \mathrm{mg} \mathrm{kg}^{-1}$ available potassium, $\mathrm{pH}$ 7.21).

In late May of 2015, 240 uniformly sized seedlings underwent different drought stress treatments. At the beginning of the experiment, the average of diameter and height of the seedlings were $0.8 \pm 0.19$ and $25 \pm 1.92 \mathrm{~cm}$ respectively. The experiment was carried out in a completely randomized design with two factors (two provenances and three watering regimes). Each

\section{Physiological parameters}

The maximum photochemical efficiency of photosystem II, xylem water potential, and gas exchanges were measured three times (once every month). Net photosynthesis $(A)$, transpiration $(E)$, stomatal conductance $\left(\mathrm{g}_{\mathrm{s}}\right)$, and intercellular $\mathrm{CO}_{2}$ concentration $\left(C_{i}\right)$ were determined using a portable photosynthesis measuring device $\mathrm{LI}$ $6400 X^{\oplus}$ (LI-COR, Lincoln, USA). Fully-developed leaves from the lower part of the stem (the same in all seedlings) were selected for gas exchange measurements (Oguchi et al. 2006). The maximum Rubisco activity, $V_{c \max }$, was estimated through the analysis of $A / C_{i}$ curves, according to Sharkey et al. (2007).

Leaf water potential $(\Psi)$ was measured using a Scholander-type pressure chamber (Skye, SKPM 1400, UK). From each seedling, five fully-developed leaves were collected. Gas exchange parameters, water potential in stable conditions of $\mathrm{CO}_{2}(350$ $\mathrm{ppm})$, relative humidity (60\% to $80 \%)$, and constant leaf temperature $\left(25^{\circ} \mathrm{C}\right.$ to $30{ }^{\circ} \mathrm{C}$ ) were measured at midday and under fulllight conditions (Xiaoling et al. 2011).

The maximum PSII photochemical efficiency in leaves adapted to darkness (for 20 minutes) was measured using a fluorometer PAM-2000 ${ }^{\oplus}(\mathrm{H}$ Walz $\mathrm{GmbH}$, Effeltrich, Germany) connected with a leaf-clip holder and with a trifurcated fiber-optic (2010-F, Walz). The maximum PSII photochemical efficiency was calculated as (eqn. 1):

$$
\frac{F_{v}}{F_{m}}=\frac{F_{m}-F_{0}}{F_{m}}
$$

where $F_{\mathrm{v}}$ was the variable fluorescence, $F_{\mathrm{m}}$ was the maximum fluorescence of the leaves adapted to darkness and $F_{0}$ was the minimum fluorescence yield in leaves adapted to darkness.

\section{Pigment content}

At the end of the experiment, fully developed leaves were collected from each seedling and their chlorophyll and carotenoid contents were extracted using acetone $(80 \%, v / v)$. The amounts of total 
chlorophyll $(a+b)$ and carotenoid contents were calculated using the Arnon's method (Arnon 1949).

\section{Proline and soluble sugar content}

Free proline content in leaves was quantified in accordance with Bates et al. (1973). To measure the content of soluble sugars, $200 \mu \mathrm{L}$ alcoholic extract (ethanol 80\%, v/v) was mixed with $3 \mathrm{~mL}$ anthrone. The soluble obtained was placed in a boiling water bath for 10 minutes and then cooled in an ice bath. The content of soluble sugars was determined using a spectrophotometer (FCC Compliance, Epoch, Biotek Instrument, USA) by reading the absorbance at $625 \mathrm{~nm}$.

\section{Lipid peroxidation, electrolyte leakage,} and ROS determination

Lipid peroxidation was measured by the concentration of MDA byproducts. First, $0.5 \mathrm{~g}$ of fresh leaf was mixed with $0.5 \%$ $(w / v)$ thiobarbituric acid solution containing $20 \%(\mathrm{w} / \mathrm{v})$ trichloroacetic acid. The mixture was heated at $95^{\circ} \mathrm{C}$ for 25 minutes and the reaction was stopped by quickly placing it in an ice-bath. The absorbance of the supernatant was read by spectrophotometer at $532 \mathrm{~nm}$ (Valentovic et al. 2006).

To determine the electrolyte leakage (EL), $100 \mathrm{mg}$ fresh leaf samples were cut into 5 $\mathrm{mm}$ length and placed in test tubes containing $10 \mathrm{~mL}$ distilled deionized water. The tubes were placed in a water bath maintained at a constant $32^{\circ} \mathrm{C}$. After two hours, the initial electrical conductivity of the medium $\left(E C_{1}\right)$ was measured using an electrical conductivity meter. Then, the samples were put in an oven at $120{ }^{\circ} \mathrm{C}$ for 120 minutes. Then, samples were cooled to 25 ${ }^{\circ} \mathrm{C}$ and the final electrical conductivity $\left(E C_{2}\right)$ was measured. The EL was calculated by the following equation (Nayyar 2003 - eqn. 2):

$$
E L(\%)=\frac{E C_{1}}{E C_{2}} \cdot 100
$$

Hydrogen peroxide $\left(\mathrm{H}_{2} \mathrm{O}_{2}\right)$ content was measured as described by Velikova et al. (2000). Leaf samples (0.2 g) were homogenized in an ice bath with $5 \mathrm{~mL}$ of $0.1 \%$ TCA and centrifuged at 12,000 $\times$ g for 15 minutes; then, $1 \mathrm{~mL}$ of the obtained supernatant was added to $1 \mathrm{~mL}$ of $10 \mathrm{mM}$ potassium phosphate buffer ( $\mathrm{pH} 7.0$ ) and $2 \mathrm{~mL}$ of $1 \mathrm{M}$ potassium iodide, and put in a dark room for one hour. The absorbance of the supernatant was read using a spectrophotometer at $390 \mathrm{~nm}$.

Superoxide radical $\left(\mathrm{O}_{2}{ }^{\circ}\right)$ content of tissue was determined in accordance with Bai et al. (2010). Briefly, $1 \mathrm{~g}$ of fresh leaf was homogenized in $4 \mathrm{~mL}$ of $65 \mathrm{mM}$ phosphate buffer ( $\mathrm{pH} 7.8)$ and centrifuged at 5,000 $\times \mathrm{g}$ for 10 minutes. Then, $1 \mathrm{~mL}$ of the obtained supernatant was mixed with $0.1 \mathrm{~mL}$ of 10 $\mathrm{mM}$ hydroxylamine chloride and $0.9 \mathrm{~mL}$ of $65 \mathrm{mM}$ phosphate buffer ( $\mathrm{pH} 7.8)$, and held for 20 minutes at $25^{\circ} \mathrm{C}$ in a water bath. Subsequently, $1 \mathrm{~mL}$ of this mixture was mixed with $1 \mathrm{~mL}$ of $17 \mathrm{mM}$ sulfanilic acid and $1 \mathrm{~mL}$ of $7 \mathrm{mM}$ a-naphthylamine, and held for 20 minutes at $25^{\circ} \mathrm{C}$. The absorbance of supernatant was read at $530 \mathrm{~nm}$. Nitrogen dioxide radical was used as a standard.

\section{Quantitative analysis of activities of antioxidant enzymes}

Fresh leaves were collected from each seedling subjected to three watering regimes and immediately put in liquid nitrogen and kept at $-80{ }^{\circ} \mathrm{C}$ for enzymes assay. Leaf tissue $(1 \mathrm{~g})$ was homogenized with 3 $\mathrm{mL} 0.05 \mathrm{mM}$ sodium phosphate buffer $(\mathrm{pH}$ 7.8) containing $1 \mathrm{mM}$ ethylenediaminetetraacetic acid (EDTA) and 2\% polyvinylpolypyrrolidone (PVPP) and centrifuged at $15,000 \times g$ for 40 minutes. The supernatant was used to determine enzyme activities.

The activity of SOD and POXs was measured in accordance with Beauchamp \& Fridovich (1971). CAT activity was determined as reported by Bergmeyer (1972). APX assay was performed in accordance with Nakano \& Asada (1981).

Determination of PAL activity, total phenol and flavonoid contents

PAL activity was determined by trans-cinnamic acid production rate in accordance with Wang et al. (2006). Total leaf phenol content was determined by the Folin-Ciocalteu method (Singleton \& Rossi 1965) and leaf flavonoid content was determined in accordance with the method suggested by Zhishen et al. (1999).

\section{Statistical analysis}

The experiment was performed in a factorial-based completely random design (CRD) with a $2 \times 3$ factorial arrangement. The data was analyzed by analysis of variance (ANOVA) using the statistical package SPSS $^{\circledast}$ ver. 16.0 (IBM, Armonk, NY, USA); the mean values were compared using Duncan's multiple range test ( $\alpha=0.05)$.

\section{Results}

\section{Growth parameters}

Typically, Chegeni seedlings had larger diameter compared with Melasyah seedlings. No significant difference were found between stem diameter of seedlings under control (W) and moderate (M) drought conditions (Fig. 1a). However, severe (S) drought significantly reduced the diameter of Chegeni seedlings, but not that of Melasyah seedlings.

Drought stress significantly reduced the height of seedlings in both populations (Fig. 1b). Severe stress (S) significantly reduced the height of seedlings when compared to control (W) and moderate (M) stress.

The total biomass of Chegeni seedlings was significantly influenced by drought stress, but Melasyah population was not (Fig. 1C). A significant interaction effect between population and drought stress was also detected for total biomass. As a result, the total seedling biomass for the Chegeni provenance was higher than that for Melasyah under control condition. In addition, severe stress (S) decreased the total biomass of Chegeni seedlings compared to moderate stress $(M)$.

\section{Physiological parameters}

In June, one month after the drought stress was applied, the net photosynthesis rate, stomatal conductance, and $V_{\text {cmax }}$ in moderate and severe drought-stressed seedlings from both provenances declined, in comparison with unstressed seedlings,
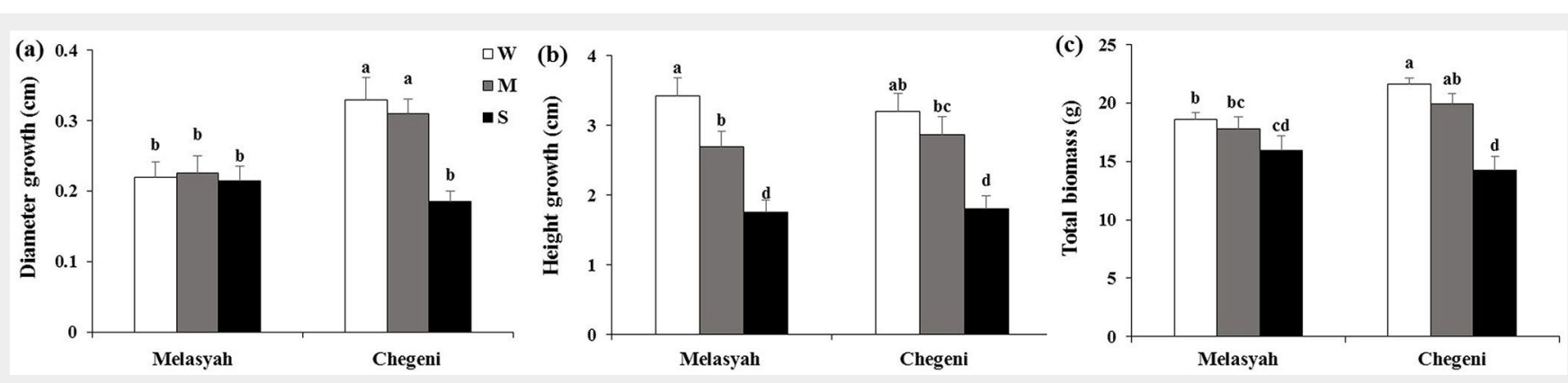

Fig. 1 - Mean values ( \pm standard error) of (a) diameter growth, (b) height growth and (c) total biomass of Persian oak seedlings from Melasyah and Chegeni provenances under different drought stress treatments. (W): irrigation to 100\% field capacity; (M): irrigation to $50 \%$ field capacity; (S): irrigation to $20 \%$ field capacity. Different letters on the top of bars indicate significant difference between treatments after Duncan's test $(\mathrm{p}<0.05, \mathrm{n}=4)$. 

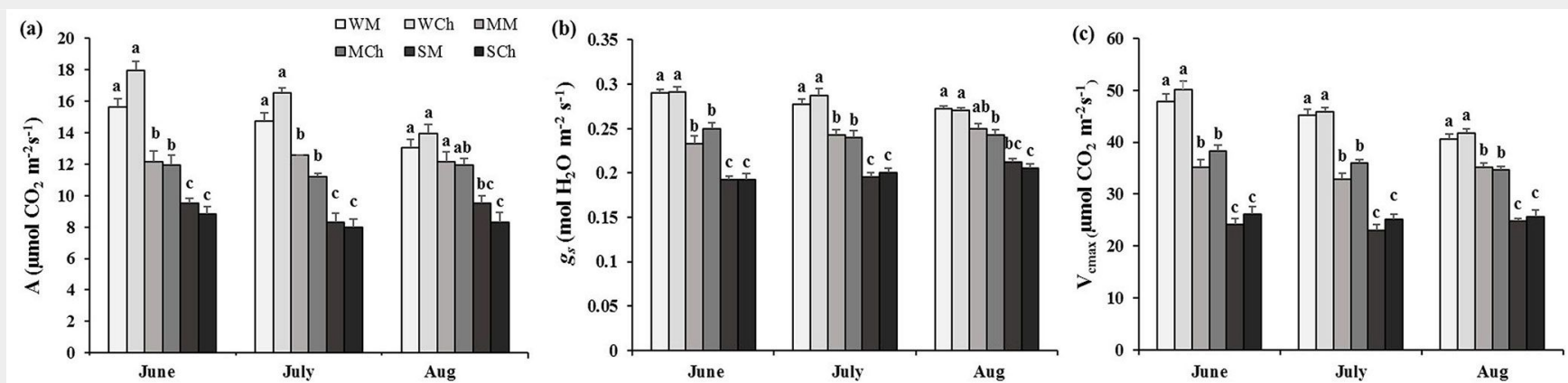

Fig. 2 - Mean values ( \pm standard error) of (a) net photosynthesis rate $(A)$, (b) stomatal conductance $\left(g_{s}\right)$ and $(c) V_{c m a x}$ in Persian oak seedlings from Melasyah (M) and Chegeni (Ch) provenances under different drought stress treatments. (W): irrigation to $100 \%$ field capacity; (M): irrigation to $50 \%$ field capacity; (S): irrigation to $20 \%$ field capacity. Different letters on the top of bars indicate significant difference between treatments after Duncan's test $(\mathrm{p}<0.05, \mathrm{n}=4)$.

and there was no significant difference between the two provenances (Fig. 2a, Fig. 2b). After two months of drought stress, in July, the gas exchange parameters were similar to those observed in June. In August (after three month of drought stress), the net photosynthesis rate declined considerably in seedlings subjected to severe drought stress (SM and SCh); however, we did not find any significant difference between moderate stress (MM and MCh) and control (WM and WCh) seedlings. Furthermore, we did not observe a significant difference of net photosynthesis after three months of drought among the two provenances. In August, stomatal conductance extensively decreased in the seedlings from Melasyah only under severe drought stress (SM). On the other hand, moderate and severe drought stress negatively affected stomatal conductance of Chegeni seedlings (MCh and SCh, respectivey). The results of $V_{\text {cmax }}$ were the same for all three months (Fig. 2C).

In June and July, the xylem water potential of seedlings from both provenances declined in response to moderate and severe drought stress. In July, Chegeni seedlings under severe drought stress showed the lowest mean value of xylem water potential and the decreasing rate was greater in this provenance in comparison with the Melasyah provenance. On the other hand, moderate drought stress only affected the xylem water potential of Chegeni provenance seedlings (Fig. 3a). The maximum
Fig. 3 - Mean values ( \pm standard error) of

(a) xylem water potential $(\psi)$ and (b) the maximum PSI photochemical efficiency in leaves of Persian oak seed lings from Melasyah

(M) and Chegeni

(Ch) provenances under different drought stress treatments. (W): irrigation to $100 \%$ field capacity; (M): irrigation to $50 \%$ field capacity ; (S): irrigation to $20 \%$ field capacity. Different letters on the top of bars indicate significant differences between treatments after Duncan's test $(p<0.05, n=4)$
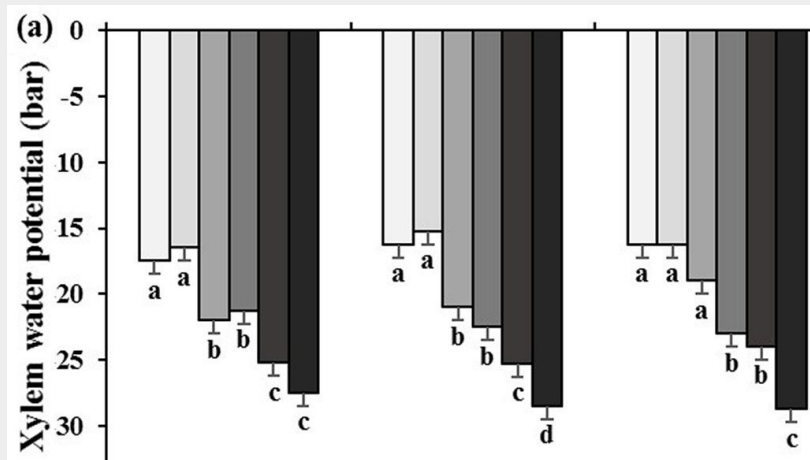

\section{-35 口WM DWCh 口MM $\mathrm{MMCh}$ 口SM $\mathrm{SCh}$}

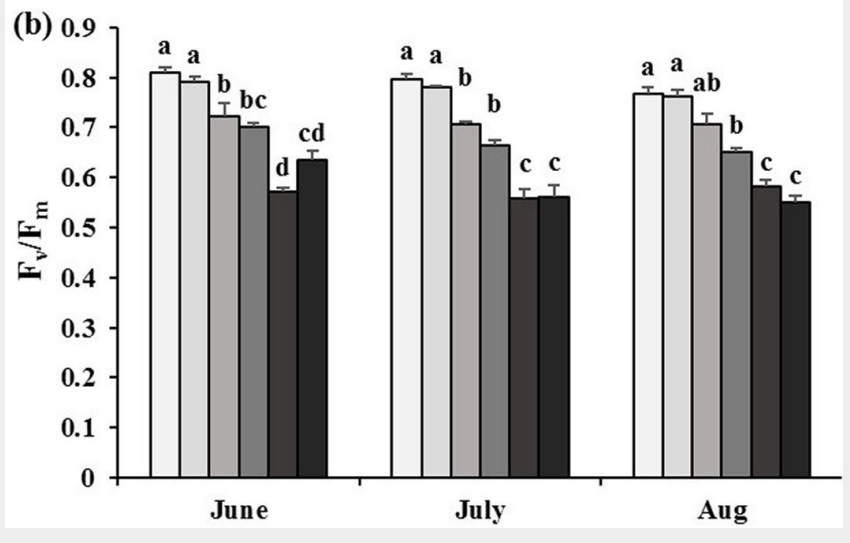

PSII photochemical efficiency in both provenances significantly decreased in response to moderate and severe drought stress when they were measured in June and July. In August, PSII in Melasyah seedlings was affected only by severe drought stress, while both moderate and severe drought stress led to a decrease in the parameter values of Chegeni seedlings at the same time (Fig. 3b).

\section{Pigment content, proline and soluble sugar concentration}

Chlorophyll and carotenoid content of the seedlings decreased in response to drought stress (Fig. 4a, Fig. 4b). Moderate or severe stress drastically decreased the chlorophyll contents of Chegeni's seedlings. However, the chlorophyll contents of Melasyah seedlings were not affected by moderate stress compared to control conditions. Furthermore, carotenoid content of Chegeni seedlings decreased more than Melasyah seedlings under stress.

Proline concentration increased in seedlings of both populations under moderate and severe drought stress (Fig. 4C). It increased in Melasyah provenance during moderate and severe stresses, while proline content of Chegeni seedlings increased just under severe drought stress.

The concentration of soluble sugars increased in seedlings of both provenances in response to drought stress, and the highest concentration of soluble sugars was recorded in Melasyah seedlings under severe stress.

\section{Cell damage and ROS concentrations}

Under drought stress, MDA content increased in seedlings of both provenances. MDA increased more in seedlings from Chegeni compared to the Melasyah provenance (Fig. 5a). Drought stress also increased EL in seedlings of both populations (Fig. 5b). The highest value of EL was detected for seedlings from Chegeni under drought stress.

Hydrogen peroxide and superoxide radical increased in response to water limitation when the seedlings of both provenances were exposed to drought stress 
Fig. 4 - Mean values ( \pm standard error) of (a) chlorophyll $a+b$ content, (b) carotenoid, (c) proline and (d) soluble sugar concentrations in leaves of Persian oak seedlings from Melasyah and Chegeni provenances under different drought stress treatments. (W): irrigation to $100 \%$ field capacity; (M): irrigation to $50 \%$ field capacity ; (S): irrigation to $20 \%$ field capacity. Different letters on the top

of bars indicate significant differences between treatments according to Duncan's test $(p<0.05, n=4)$. error) of MDA (a), electrolyte leakage (b), hydrogen peroxide (c) and superoxide radical (d) in leaves of

Persian oak seedlings from Mela-

syah and Chegeni provenances under different drought stress treatments. (W): irrigation to $100 \%$ field capacity; (M): irrigation to $50 \%$ field capacity; (S): irrigation to $20 \%$ field capacity). Different letters on the top of bars indicate significant dif-

ferences between treatments according to Duncan's test $(p<0.05$, $\mathrm{n}=4)$.

Fig. 6 - Mean values ( \pm standard error) of antioxidant enzyme activities (a: POD; b: SOD; c: CAT; d: APX)

in leaves of Persian oak seedlings from Melasyah and Chegeni prove-

nances under different drought stress treatments. (W): irrigation to $100 \%$ field capacity; (M): irrigation to $50 \%$ field capacity; (S): irrigation to $20 \%$ field capacity). Different letters on the top of bars indicate signifi-

cant differences between treatments according to Duncan's test $(p<0.05, n=4)$.
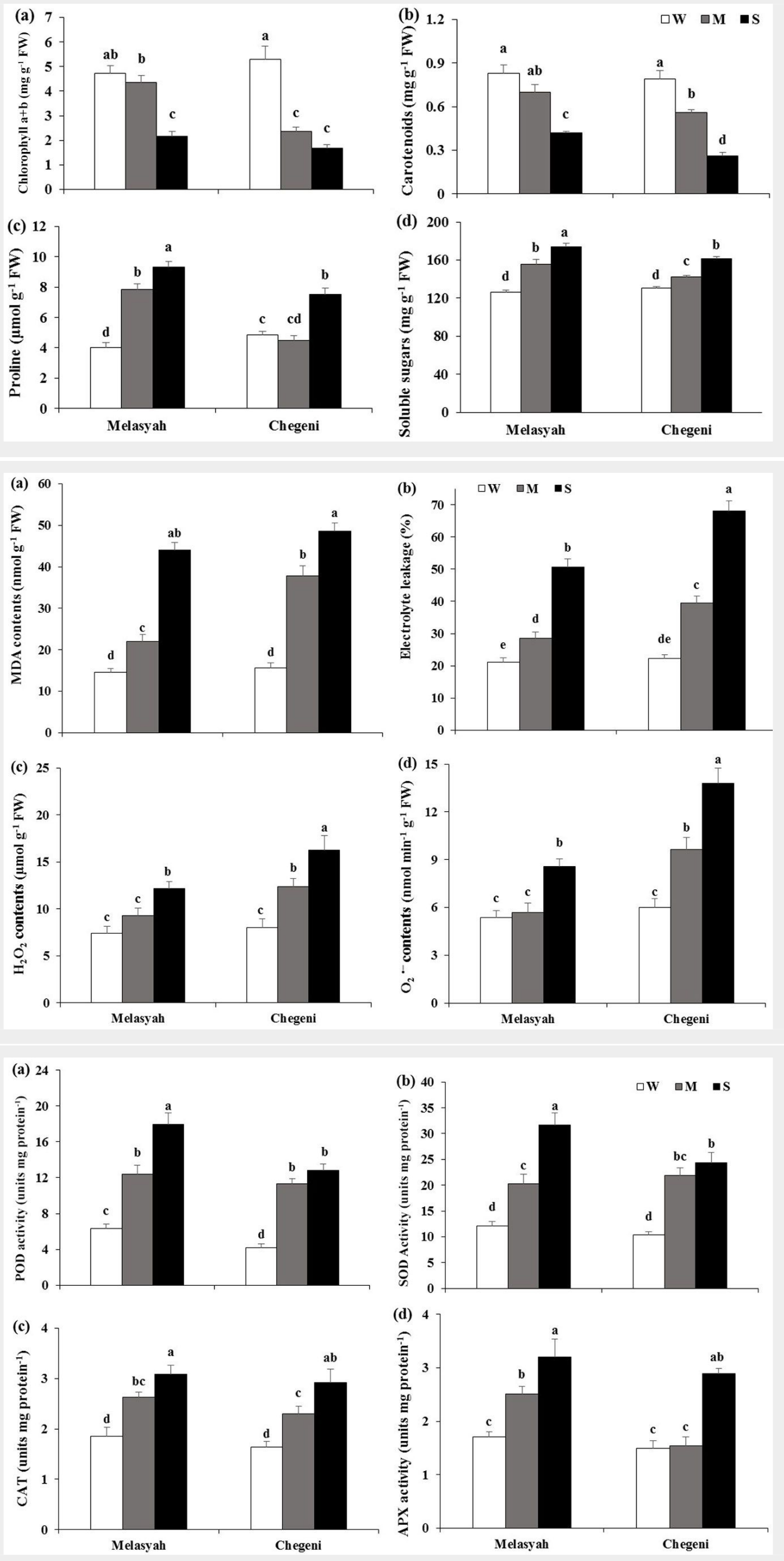

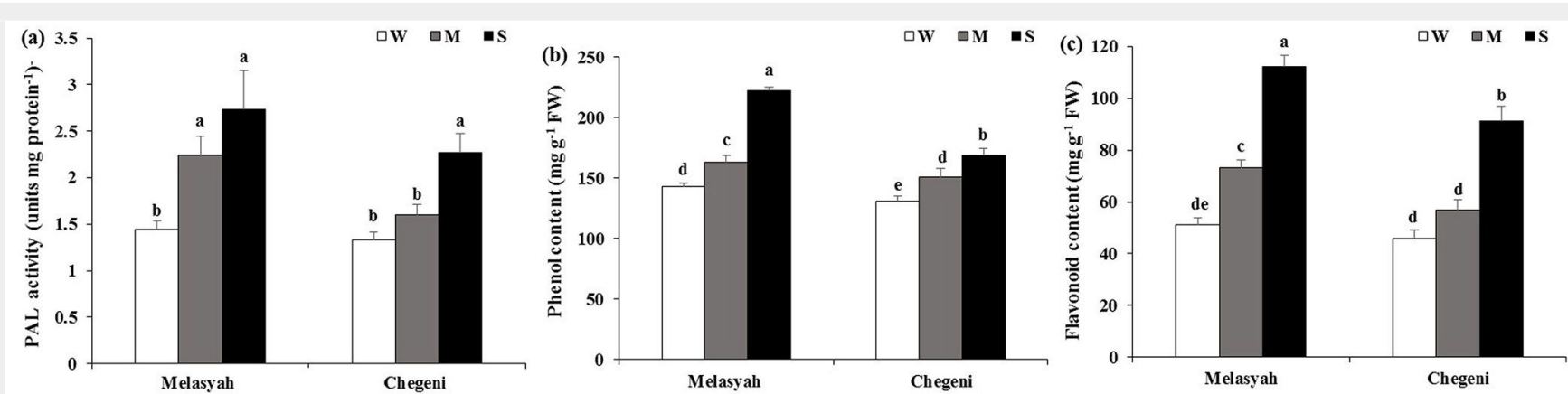

Fig. 7 - Mean values ( \pm standard error) of (a) PAL enzyme activity, (b) total phenol and (c) flavonoid content in leaves of Persian oak seedlings from Melasyah and Chegeni provenances under different drought stress treatments. (W): irrigation to $100 \%$ field capacity; (M): irrigation to $50 \%$ field capacity; (S): irrigation to $20 \%$ field capacity). Different letters on the top of bars indicate significant differences between treatments according to Duncan's test $(p<0.05, n=4)$.

(Fig. 5C, Fig. 5d). The production of hydrogen peroxide and superoxide radical in response to moderate drought stress increased in seedlings from Chegeni. Under both drought treatments, ROS production was higher in Chegeni seedlings as compared to Melasyah seedlings.

\section{Antioxidant enzymes}

The activities of POD and SOD were higher when seedlings were exposed to moderate and severe water stress compared to well-watered seedlings, and the highest enzyme activities were recorded in Melasyah seedlings subjected to severe drought stress (Fig. 6a, Fig. 6b). The Melasyah seedlings subjected to both drought treatments showed higher activity of CAT than well-irrigated seedlings, while the enzyme activity in Chegeni seedlings just increased under severe water limitations (Fig. 6c). In the Chegeni population, there was no difference in APX activity between moderately and non-stressed seedlings, but the enzyme activity was highest in the severe drought treatment (Fig. 6d).

\section{PAL activity, total phenol and flavonoid content}

PAL activity increased after drought stress in seedlings of both populations. Although Melasyah seedlings had higher levels of PAL activity under moderate and severe drought stress in comparison with control seedlings, no difference was found in well-watered and moderate droughtstressed seedlings from Chegeni provenance and the enzyme activity just increased in response to severe stress (Fig. 7a).

In both populations, total phenol content in stressed seedlings was higher than in control seedlings (Fig. 7b). The highest phenol content was found in Melasyah seedlings subjected to severe stress.

Both levels of drought stress led to a significant increase in flavonoid content of Melasyah seedlings in comparison with control seedlings, whereas flavonoid content in Chegeni seedlings significantly increased only in response to severe drought stress (Fig. 7C). Under both levels of water limitation, the foliar flavonoid content of Melasyah seedlings was higher than of Chegeni seedlings.

\section{Discussion}

Populations from high precipitation regions are reported to be less resistant to drought than those growing under low precipitation regimes (Zarafshar et al. 2014). In this study, we compared two Persian oak provenances from different precipitation regimes, observing significant differences in terms of growth, physiological, and biochemical differences; hence, a local adaptation to drier conditions may be hypothesized. Under water limitations, the Melasyah provenance significantly differed from the Chegeni provenance, probably as a result of its origin from a lower precipitation region. Our findings are supported by the results of Wanjiku \& Bohne (2017), who worked on growth and drought responses of three Prunus spinosa L. ecotypes from Germany and Italy. They reported that $P$. spinosa tends to vary in susceptibility to drought because of local adaptation.

As expected, photosynthetic performance and aboveground growth of oak seedlings from both provenances significantly declined when exposed to severe drought stress in comparison with control seedlings. Diameter growth significantly decreased by $52.52 \%$ in Chegeni seedlings under severe drought stress compared with non-stressed seedlings, while the height growth of seedlings from both provenances declined under moderate and severe water limitations (by $18 \%$ and $51 \%$ at Melasyah and $18 \%$ and $39 \%$ at Chegeni provenance under moderate and severe drought stress, respectively). Moreover, the total seedling biomass for Melasyah and Chegeni provenances declined by $14 \%$ and $34 \%$ respectively, when subjected to severe drought stress. The reduction in plant growth is a common response to water shortage as a result of reduced photosynthesis (Ghanbary et al. 2017), which is positively correlated with plant growth (Manes et al. 2006). In this study, the results of morphological analysis showed that the Chegeni population was more sen- sitive to drought stress compared to the Melasyah population.

Drought is one of the most important abiotic stresses in distribution range of oak species and leads to a decrease in gas exchange parameters (including photosynthesis rate, stomatal conductance, and transpiration rate - Cotrozzi et al. 2016, Ghanbary et al. 2017). However, the negative effects can vary depending on drought severity and genotype. In this study, the rate of photosynthesis and the stomatal conductance of oak seedlings declined in response to drought stress, especially when exposed to severe drought. Furthermore, the decreasing rate of the photosynthetic parameters was more prominent in seedlings from Chegeni than from Melasyah provenance. Stomatal conductance is a primary driver of hydrological changes that control plant response to environmental stress, and is highly correlated with the photosynthesis rate as well (Flexas et al. 2014). The reduced rate of photosynthesis can be associated with the decrease in stomatal conductance, transpiration, and mesophilic changes, such as changes in $C_{i}$ and the reduced apparent $\mathrm{V}_{\mathrm{cmax}}$ (Cotrozzi et al. 2016), finally leading to a decrease in photochemical efficiency of PS II.

It is well known that the decrease in water potential and maintenance of water relations is one of the plant strategies in response to water limitation, which finally helps develop resistance to drought stress. Our findings revealed that Persian oak seedlings reduced xylem water potential when they were exposed to severe drought stress. Moreover, xylem water potential of Chegeni seedlings under drought stress was more negative compared with those of Melasyah seedlings. The reduced water potential of plants under drought is a common physiological response to perform osmoregulation and maintain plant water so as to enhance drought resistance, as reported in different studies on oak species (Cotrozzi et al. 2016). We surveyed the stability of PSII in seedlings by means of $F_{\mathrm{v}} / F_{\mathrm{m}}$ measurement because the photochemical efficiency of photosystem II is among the most important components of 
the photosynthetic apparatus. We clearly observed a decrease of $F_{\mathrm{v}} / F_{\mathrm{m}}$ in seedlings from both provenances under water limitation treatments. Hence, it can be hypothesized that a reduction in $F_{\mathrm{v}} / F_{\mathrm{m}}$ could represent a deep disorder in PSII. Moreover, Boussadia et al. (2008) stated that the reduction in $F_{v} / F_{m}$ is related to down-regulation of PSII, reflecting a protective or regulative mechanism to preclude energy loss and damage to photosynthetic apparatus. Our results support the last findings about changes in PSII when plants were subjected to drought stress (Disante et al. 2011).

Pigment content is an important indicator of the plant status, and can be used to survey the capability and activity of plant photosynthesis (Fassnacht et al. 2015). The reduction in chlorophyll content under drought stress is a common response following biotic or abiotic stresses because of photo-oxidation, chlorophyll degradation, or impaired chlorophyll biosynthesis (Smirnoff 1993). In out study, chlorophyll $a+b$ and carotenoid contents of Persian oak seedlings from both populations declined under drought stress treatments, though the decreasing rate was greater in the Chegeni population. In addition, a decline in pigment content under moderate drought stress was recorded only for the Chegeni provenance. The reduction in chlorophyll and carotenoid content in response to water shortage have been also reported by previous studies (Ahmed et al. 2009).

An increase in proline content under water limitation seems related to drought resistance in plants (Liu et al. 2011). Based on out results, Melasyah seedlings had higher proline content compared to the Chegeni provenance. The increase of proline under water limitation was repeatedly observed in other plants (Cotrozzi et al. 2016), where it acts as an osmotic molecule and protects the plant cell from ROS (Szabados \& Savoure 2010).

We observed that drought stress stimulated an increase in soluble sugar in Persian oak leaves as compared with unstressed seedlings. Furthermore, soluble sugar content was higher in Melasyah than in Chegeni seedlings. Typically, drought stress accelerates soluble sugar content in the leaf and subsequently leads to induced osmotic adjustment (Holland et al. 2016). The accumulation of soluble sugar promotes water penetration and finally maintains cell volume to avoid wilting (Holland et al. 2016). Not only are soluble sugars metabolic sources and compounds of cell structure, they also act as substrates for cellular respiration (Manes et al. 2006).

Electrolyte leakage is an indicator of cell integrity and cellular membrane stability which reflects the degree of damage to the plant by stress agents (Kocheva et al. 2004). Generally, the content of MDA byproducts is a measure of the degree of lipid peroxidation caused by oxidative stress (Lima et al. 2002). In the current study, the increase in MDA content in response to drought stress occurred in stressed seedlings of both populations, and was concomitant with the increase in electrolyte leakage. The result indicates that lipid peroxidation increased membrane permeability. In fact, lipid peroxidation determines changes in cellular membrane causing an increase in electrolyte leakage and osmotic imbalance (Santos et al. 2005). Previous studies have reported a similar increase in MDA content and electrolyte leakage in plants subjected to water limitation stress (Cotrozzi et al. 2016, Liu et al. 2011).

ROS (including superoxide radicals and hydrogen peroxide) are the first messengers in plants subjected to drought stress (Talbi et al. 2015), and their increase in response to drought stress has been proved (Shi et al. 2015). In our study, the enhancement of superoxide radicals and hydrogen peroxide content in drought treatments was expected, indicating that oak seedlings were subjected to oxidative stress. ROS causes lipid peroxidation by stimulating decomposition of unsaturated lipids and finally has negative effects on the structure, fluidity, and integrity of plant cells (Jin et al. 2015). Like MDA and electrolyte leakage, superoxide radicals and hydrogen peroxide content only increased in the Chegeni provenance under moderate water limitation, while Melasyah seedlings showed more resistance under the same condition.

Antioxidant enzymes (peroxidase, superoxide dismutase, catalase, etc.) are part of the most important metabolic pathways for the removal of ROS and limitation of lipid peroxidation (Liu et al. 2011). In this study, antioxidant enzyme activities, including peroxidase, superoxide dismutase, catalase, and ascorbate peroxidase, increased when the oak seedlings were exposed to the water limitation.

The increase in antioxidant enzymes in Persian oak seedlings under drought condition could be an adaption mechanism to face the high production of ROS. Among all the antioxidant enzymes, superoxide dismutase converts superoxide radicals to hydrogen peroxide, which subsequently should be scavenged to water and molecular oxygen by the others like POD, CAT, and APX (Ozkur et al. 2009). Catalase is mainly located in peroxisome, where its main function is to remove hydrogen peroxide $\left(\mathrm{H}_{2} \mathrm{O}_{2}\right.$-detoxifying), while peroxidase converts hydrogen peroxide to water by means of some available reductions in the cell (Mittler 2002). Similarly to our results, other studied have reported an increase in antioxidant enzyme activities in plants in response to water limitation stress (He et al. 2017). Our results showed that Melasyah seedlings had higher antioxidant activity than Chegeni seedlings.

In the current study, the increase in PAL activity and accumulation of phenolic com- ponents in leaves of Persian oak seedlings under severe drought conditions reflects changes in the phenylpropanoid pathway. Under drought stress, total phenol and flavonoid contents of Melasyah seedlings were higher than those of Chegeni seedlings. In fact, the increase in PAL activity determines the activation of the phenylpropanoid pathway, and thus causes accumulation of phenolic and flavonoid compounds. Phenolic compounds are secondary metabolites with antioxidant effects in plants exposed to oxidative stress (Mansori et al. 2015). In line with our findings, an increase in phenolic compounds associated with increasing PAL in drought-stressed plants have been reported (Ahmadi et al. 2014).

\section{Conclusions}

We evaluated morpho-physiological and biochemical responses to drought of two provenances of Persian Oak to test for their local adaption to contrasting climatic conditions. Overall, our results show that there is a systematic relationship between responses to drought stress and provenance. Growth parameters, gas exchange, and pigment content of seedlings from Melasyah provenance (drier climate) were less affected by drought stress when were compared with those from Chegeni provenance (wetter climate). Our findings revealed a significant relationship between the mean annual precipitations of Persian oak stands and their drought tolerance. It can be concluded that the climatic condition of Persian oak stands is an important factor to be be considered by forest managers who are responsible for establishment and restoration programs.

\section{Acknowledgements}

The authors acknowledge the help of Dr. Ehsan Ghanbary, Mr. Jebreil, and Dr. Mohammad Khezry in providing plant materials and soil preparation, greenhouse maintenance, and watering.

\section{References}

Ahmadi R, Kiadaliri H, Mataji A, Kafaki S (2014). Oak forest decline zonation using AHP model and GIS technique in Zagros Forests of Ilam Province. Journal of Biodiversity and Environmental Sciences 4: 141-150. - [online] URL: http://citeseerx.ist.psu.edu/viewdoc/download? doi=10.1.1.654.8481\&rep=rep1\&type=pdf Ahmed C, Ben F, Rouina B, Sensoy S, Boukhris M, Abdallah F (2009). Changes in gas exchange, proline accumulation and antioxidative enzyme activities in three olive cultivars under contrasting water availability regimes. Environment and Experimental Botany 67: 345-352. - doi: 10.101 6/j.envexpbot.2009.07.006

Arnon DI (1949). Copper enzymes in isolated chloroplasts. Polyphenoloxidase in Beta vulgaris. Plant Physiology 24: 1-15. - doi: 10.1104/pp.2 4.1.1

Bai T, Li C, Ma F, Feng F, Shu H (2010). Responses of growth and antioxidant system to root-zone hypoxia stress in two Malus species. Plant Soil 
327: 95-105. - doi: 10.1007/s11104-009-0034-X Bates LS, Waldren RP, Teare ID (1973). Rapid determination of free proline for water-stress studies. Plant Soil 39: 205-207. - doi: 10.1007/BF 00018060

Beauchamp C, Fridovich I (1971). Superoxide dismutase: improved assays and an assay applicable to acrylamide gels. Analytical Biochemistry 44: 276-287. - doi: 10.1016/0003-2697(71)903708

Bergmeyer HU (1972). Methoden der enzymatis chen Analyse, 2. Auflage [Methods of enzy matic analysis, $2^{\text {nd }}$ edition]. Akademie-Verlag, Berlin, Germany, pp. 318. [in German]

Boussadia O, Mariem F, Ben Mechri B, Boussetta W, Braham M, Ben El Hadj S (2008). Response to drought of two olive tree cultivars (cv. Koroneki and Meski). Scientia Horticulturae 116: 388-393. - doi: 10.1016/j.scienta.2008.02.016 Cotrozzi L, Remorini D, Pellegrini E, Landi M, Massai R, Nali C, Guidi L, Lorenzini G (2016). Variations in physiological and biochemical traits of oak seedlings grown under drought and ozone stress. Physiologia Plantarum 157: 69-84. - doi: 10.1111/ppl.12402

Disante KB, Fuentes D, Cortina J (2011). Response to drought of Zn-stressed Quercus suber L. seedlings. Environmental and Experimental Botany 70: 96-103. - doi: 10.1016/j.envexpbot. 2010.08.008

Ebadzad G, Medeira C, Maia I, Martins J, Cravador A (2015). Induction of defense responses by cinnamomins against Phytophthora cinnamomi in Quercus suber and Quercus ilex subs. rotundifolia. European Journal of Plant Pathology 143: 705-723. - doi: 10.1007/s10658-015-07219

Fassnacht FE, Stenzel S, Gitelson AA (2015). Nondestructive estimation of foliar carotenoid content of tree species using merged vegetation indices. Journal of Plant Physiology 176: 210-217. - doi: 10.1016/j.jplph.2014.11.003

Fini A, Bellasio C, Pollastri S, Tattini M, Ferrini F (2013). Water relations, growth, and leaf gas exchange as affected by water stress in Jatropha curcas. Journal of Arid Environments 89: 21-29. - doi: 10.1016/j.jaridenv.2012.10.009

Flexas J, Diaz-Espejo A, Gago J, Gallé A, Galmés J, Gulías J, Medrano H (2014). Photosynthetic limitations in Mediterranean plants: a review. Environmental and Experimental Botany 103: 12-23. - doi: 10.1016/j.envexpbot.2013.09.002 Ghanbary E, Tabari Kouchaksaraei M, Mirabolfathy M, Modarres Sanavi SAM, Rahaei M (2017). Growth and physiological responses of Quercus brantii seedlings inoculated with Biscogniauxia mediterranea and Obolarina persica under drought stress. Forest Pathology 47 (5): e12353. - doi: 10.1111/efp.12353

He F, Sheng M, Tang M (2017). Effects of Rhizophagus irregularis on photosynthesis and antioxidative enzymatic system in Robinia pseudoacacia L. under drought stress. Frontiers in Plant Science 8: 183. - doi: 10.3389/fpls.2017.0 0183

Hessini K, Martínez JP, Gandour M, Albouchi A, Soltani A, Abdelly C (2009). Effect of water stress on growth, osmotic adjustment, cell wall elasticity and water-use efficiency in Spartina alterniflora. Environmental and Experimental Botany 67: 312-319. - doi: 10.1016/j.envexpbot.2
009.06.010

Holland V, Koller S, Lukas S, Brüggemann W (2016). Drought-and frost-induced accumulation of soluble carbohydrates during accelerated senescence in Quercus pubescens. Trees 30: 215-226. - doi: 10.1007/s00468-015-1290-4 Hoshika Y, Omasa K, Paoletti E (2013). Both ozone exposure and soil water stress are able to induce stomatal sluggishness. Environmental and Experimental Botany 88: 19-23. - doi: 10.1016/j.envexpbot.2011.12.004

Hu L, Wang Z, Huang B (2010). Diffusion limitations and metabolic factors associated with inhibition and recovery of photosynthesis from drought stress in a $C_{3}$ perennial grass species. Physiologia Plantarum 139: 93-106. - doi: 10.1111/ j.1399-3054.2010.01350.x

Jin R, Shi H, Han C, Zhong B, Wang Q, Chan Z (2015). Physiological changes of purslane (Portulaca oleracea L.) after progressive drought stress and rehydration. Scientia Horticulturae 194: 215-221. - doi: 10.1016/j.scienta.2015.08.023 Kocheva K, Lambrev P, Georgiev G, Goltsev V, Karabaliev M (2004). Evaluation of chlorophyll fluorescence and membrane injury in the leaves of barley cultivars under osmotic stress. Bioelectrochemistry 63: 121-124. - doi: 10.1016/j.bioelechem.2003.09.020

La Porta N, Capretti P, Thomsen IM, Kasanen R, Hietala AM, Von Weissenberg K (2008). Forest pathogens with higher damage potential due to climate change in Europe. Canadian Journal of Plant Pathology 30: 177-195. - doi: 10.1080/07 060661.2008.10540534

Lima ALS, DaMatta FM, Pinheiro HA, Totola MR, Loureiro ME (2002). Photochemical responses and oxidative stress in two clones of Coffea canephora under water deficit conditions. Environmental and Experimental Botany 47: 239247. - doi: 10.1016/So098-8472(01)00130-7

Liu C, Liu Y, Guo K, Fan D, Li G, Zheng Y, Yu L, Yang $R$ (2011). Effect of drought on pigments, osmotic adjustment and antioxidant enzymes in six woody plant species in karst habitats of southwestern China. Environmental and Experimental Botany 71: 174-183. - doi: 10.1016/j.env expbot.2010.11.012

Manes F, Vitale M, Donato E, Giannini M, Puppi G (2006). Different ability of three Mediterranean oak species to tolerate progressive water stress. Photosynthetica 44: 387-393. - doi: 10.1007/s11099-006-0040-7

Mansori M, Chernane $\mathrm{H}$, Latique S, Benaliat A, Hsissou D, El Kaoua M (2015). Seaweed extract effect on water deficit and antioxidative mechanisms in bean plants (Phaseolus vulgaris L.). Journal of Applied Phycology 27: 1689-1698. doi: 10.1007/s10811-014-0455-7

Mittler R (2002). Oxidative stress, antioxidants and stress tolerance. Trends in Plant Science $7:$ 405-410. - doi: 10.1016/S1360-1385(02)02312-9 Nakano Y, Asada K (1981). Hydrogen peroxide is scavenged by ascorbate-specific peroxidase in spinach chloroplasts. Plant and Cell Physiology 22: 867-880. - doi: 10.1093/oxfordjournals.pcp. a076232

Nayyar H (2003). Accumulation of osmolytes and osmotic adjustment in water-stressed wheat (Triticum aestivum) and maize (Zea mays) as affected by calcium and its antagonists. Environmental and Experimental Botany 50: 253-
264. - doi: 10.1016/So098-8472(03)00038-8 Oguchi R, Hikosaka K, Hiura T, Hirose T (2006). Leaf anatomy and light acclimation in woody seedlings after gap formation in a cool-temperate deciduous forest. Oecologia 149: 571-582. doi: 10.1007/s00442-006-0485-1

Ozkur O, Ozdemir F, Bor M, Turkan I (2009). Physiochemical and antioxidant responses of the perennial xerophyte Capparis ovata Desf. to drought. Environmental and Experimental Botany 66: 487-492. - doi: 10.1016/j.envexpbot.2 009.04 .003

Porth I, Scotti-Saintagne C, Barreneche T, Kremer A, Burg K (2005). Linkage mapping of osmotic stress induced genes of oak. Tree Genetics and Genomes 1: 31-40. - doi: 10.1007/s11295005-0005-1

Santos C, Fragoeiro S, Phillips A (2005). Physiological response of grapevine cultivars and a rootstock to infection with Phaeoacremonium and Phaeomoniella isolates: an in vitro approach using plants and calluses. Scientia Horticulturae 103: 187-198. - doi: 10.1016/j.scienta.20 04.04 .023

Sharkey TD, Bernacchi CJ, Farquhar GD, Singsaas EL (2007). Fitting photosynthetic carbon dioxide response curves for $\mathrm{C}_{3}$ leaves. Plant, Cell and Environment 30: 1035-1040. - doi: 10.1111/j. 1365-3040.2007.01710.x

Shi H, Ye T, Song B, Qi X, Chan Z (2015). Comparative physiological and metabolomic responses of four Brachypodium distachyon varieties contrasting in drought stress resistance. Acta Physiologiae Plantarum 37: 1-12. - doi: 10.1007/s11738014-1746-y

Shukla N, Awasthi RP, Rawat L, Kumar J (2012). Biochemical and physiological responses of rice (Oryza sativa L.) as influenced by Trichoderma harzianum under drought stress. Plant Physiology and Biochemistry 54: 78-88. - doi: 10.1016/j. plaphy.2012.02.001

Singleton VL, Rossi JA (1965). Colorimetry of total phenolics with phosphomolybdic-phosphotungstic acid reagents. American Journal of Enology and Viticulture 16: 144-158. [online] URL: http://www.ajevonline.org/content/16/3/1 44.short

Smirnoff N (1993). The role of active oxygen in the response of plants to water deficit and desiccation. New Phytologist 125: 27-58. - doi: 10.1111/j.1469-8137.1993.tbo3863.x

Sturrock RN, Frankel SJ, Brown AV, Hennon PE, Kliejunas JT, Lewis KJ, Worrall JJ, Woods AJ (2011). Climate change and forest diseases. Plant Pathology 60: 133-149. - doi: 10.1111/j.13653059.2010.02406.x

Szabados L, Savoure A (2010). Proline: a multifunctional amino acid. Trends in Plant Science 15: 89-97. - doi: 10.1016/j.tplants.2009.11.009 Talbi S, Romero-Puertas MC, Hernández A, Terrón L, Ferchichi A, Sandalio LM (2015). Drought tolerance in a Saharian plant Oudneya africana: role of antioxidant defences. Environmental and Experimental Botany 111: 114-126. - doi: 10.1016/j.envexpbot.2014.11.004

Valentovic P, Luxova M, Kolarovic L, Gasparikova $O$ (2006). Effect of osmotic stress on compatible solutes content, membrane stability and water relations in two maize cultivars. Plant Soil and Environment 52: 186-191. - doi: 10.1111/j.1747-0765.2006.00031.x 
Velikova V, Yordanov I, Edreva A (2000). Oxidative stress and some antioxidant systems in acid rain-treated bean plants: protective role of exogenous polyamines. Plant Science 151: 5966. - doi: 10.1016/S0168-9452(99)00197-1

Wanjiku JG, Bohne H (2017). Growth and drought responses of three Prunus spinosa $\mathrm{L}$. ecotypes. African Journal of Horticulture Science 12: 40-50. [online] URL: http://www.ha kenya.net/ajhs/index.php/ajhs/article/view/184 Wang JW, Zheng LP, Wu JY, Tan RX (2006). Involvement of nitric oxide in oxidative burst, phenylalanine ammonia-lyase activation and
Taxol production induced by low-energy ultrasound in Taxus yunnanensis cell suspension cultures. Nitric Oxide 15: 351-358. - doi: 10.1016/j.ni ox.2006.04.261

Xiaoling L, Ning L, Jin Y, Fuzhou Y, Faju C, Fangqing $C$ (2011). Morphological and photosynthetic responses of riparian plant Distylium chinense seedlings to simulated autumn and winter flooding in Three Gorges Reservoir region of the Yangtze River, China. Acta Ecologica Sinica 31: 31-39. - doi: 10.1016/j.chnaes.2010.11. 005

Zarafshar M, Akbarinia M, Askari H, Hosseini SM,
Rahaie M, Struve D, Striker GG (2014). Morphological, physiological and biochemical responses to soil water deficit in seedlings of three populations of wild pear (Pyrus boisseriana). Biotechnology, Agronomy, Society and Environment 18: 353-366. [online] URL: http:// hdl.handle.net/11336/4346

Zhishen J, Mengcheng T, Jianming W (1999). The determination of flavonoid contents in mulberry and their scavenging effects on superoxide radicals. Food Chemistry 64: 555-559. - doi: 10.1016/S0308-8146(98)00102-2 